\title{
CRIANÇAS E ADOLESCENTES QUE VOAM EM JAULAS: A TECNOLOGIA PROMOVENDO A LIBERDADE NO HOSPITAL
}

\author{
Ercília Maria Angeli Teixeira de Paula*
}

\begin{abstract}
RESUMO: O objetivo desse artigo é analisar as oportunidades que os meios de comunicação oferecem às crianças e adolescentes hospitalizados. O texto reflete a experiência da autora como professora hospitalar e pesquisadora em hospitais de diferentes regiões do Brasil: Brasília (DF), São Luís (MA), Salvador (BA) e Ponta Grossa (PR). Nestes locais, os instrumentos tecnológicos auxiliavam as crianças e adolescentes tanto no entretenimento, quanto na mudança de atitudes e comportamentos. A conclusão encontrada foi que a tecnologia no ambiente hospitalar era um instrumento de inclusão social e proporcionava às crianças e adolescentes liberdade e superação de desafios nos ambientes hospitalares repletos de limitações.
\end{abstract}

Palavras-chave: Criança. Adolescente. Tecnologia. Escola no hospital.

Children AND TEenagers WHO FLy IN CAGES: TECHNOLOGY PROVIDING FREEDOM IN HOSPITAL

ABSTRACT: The aim of this article is to analyze the opportunities that the media offer to children and teenagers in hospital. The text reflects the author's experience as a hospital teacher and researcher in hospitals in different regions of Brazil: Brasília (DF), São Luís (MA), Salvador (BA), and Ponta Grossa (PR). In those areas, technology instruments helped children and teenagers, both in terms of getting entertainment and changing their attitudes and behaviors. The conclusion was that technology in the hospital environment was a social

Doutora em Educação e docente do Departamento de Educação e do Programa de Pós-Graduação em Educação da Universidade Estadual de Ponta Grossa (UEPG). E-mail: erciliapaula@terra.com.br 
Crianças e adolescentes que voam em jaulas: a tecnologia promovendo a liberdade...

inclusion instrument and provided children and teenagers with freedom and an opportunity to overcome challenges in hospital environments with plenty of limitations.

Key words: Child. Teenager. Technology. School in hospital.

\section{A introdução da tecnologia nos hospitais}

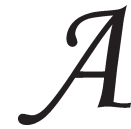

té bem pouco tempo atrás, as enfermarias dos hospitais brasileiros eram caracterizadas pelos cuidados com o resguardo, isolamento e o silêncio para com as pessoas enfermas. Nas últimas décadas, com o desenvolvimento de projetos de humanização e políticas públicas voltadas para atender aos direitos dos pacientes, a tecnologia vem assumindo um importante papel nas instituiçōes hospitalares. Ela tem sido utilizada tanto para o diagnóstico e cura das doenças, como para entreter os pacientes.

Com o objetivo de tornar os ambientes mais acolhedores, os hospitais têm buscado várias maneiras para humanizar estes espaços. A concepção de paciente vem sendo modificada. Eles já não são mais vistos como pessoas que esperam sua recuperação com apatia, mas são tratados como agentes expressivos nos seus processos de cura. O período da hospitalização também já não é mais concebido como de isolamento social.

Estas modificaçôes de estruturas e comportamentos se fazem presentes desde a re-estruturação dos espaços físicos dos hospitais até a contratação de equipes multidisciplinares. Atualmente, nas salas de espera e nas enfermarias, é comum encontrar aparelhos eletrônicos como televisão, videocassetes, DVDs, computadores e videogames que têm sido utilizados para informar e distrair os pacientes enquanto aguardam suas consultas ou durante o período em que estão hospitalizados.

Uma das manifestações que demonstram este re-ordenamento dos ambientes hospitalais brasileiros é a Lei n. 11.104. De acordo com Santiago (2007), esta lei tornou obrigatória a instalação de brinquedotecas nestes contextos e representa uma conquista no processo de modificação das estruturas hospitalares. Paralelamente a esta iniciativa, a inserção de profissionais de diferentes áreas, como professores, clowns, psicólogos, musicoterapeutas, arte educadores, artistas, entre outros, têm possibilitado novas interações nestes cenários. 
Neste artigo, serão apresentadas reflexôes que expressam uma trajetória profissional de treze anos de atuação como professora e pesquisadora da educação para crianças e adolescentes hospitalizados em quatro estados do Brasil.

\section{A inserção profissional no hospital e a complexidade deste contexto}

A trajetória de trabalho com a educação nos hospitais surgiu a partir da aprovação, no ano de 1994, em um concurso público para professores do Hospital Sarah das Doenças do Aparelho Locomotor. A vaga era para trabalhar no Hospital de São Luís do Maranhão. Cabe destacar que, nos cursos de Pedagogia daquela época, pouco se discutia sobre a educação para crianças e adolescentes em hospitais. Desta maneira, a aprovação neste concurso representava uma oportunidade de atuar em uma área ainda desconhecida. Este desafio me levou a atravessar fronteiras geográficas para entender o significado destas práticas educativas. A construção de conhecimentos neste campo de estudos também tem permitido a difusão de idéias que são compartilhadas nos encontros e eventos desta área, para acadêmicos e interessados no assunto.

Durante o período de 1994 a 1997, a experiência como professora hospitalar no Hospital Sarah possibilitou o conhecimento da realidade de crianças e adolescentes hospitalizados em Brasília (durante três meses no período de treinamento no Hospital) e, posteriormente, na cidade de São Luís do Maranhão. Nos anos de 1998 a 2000, já como professora universitária, por meio de um Projeto de Extensão Pedagogia Hospitalar da Universidade Estadual de Ponta Grossa (UEPG), no Paraná, realizava práticas lúdicas em dois hospitais da cidade: Hospital da Criança (hospital público) e na Clínica Pinheiros (hospital particular). Nestes hospitais, foi possível entender a dinâmica e a característica dos serviços de saúde do estado do Paraná. Durante os anos de 2001 a 2005, a realização da tese de doutorado e a pesquisa no Hospital da Criança das Obras Sociais de Irmã Dulce, na cidade de Salvador, na Bahia, trouxeram elementos significativos para entender a condição das crianças e adolescentes hospitalizados em nosso país. Atualmente, após retornar à UEPG, fui convidada, no ano de 2006, para implantar uma brinquedoteca no Hospital Bom Jesus - uma instituição filantrópica da cidade. Por meio do projeto de extensão "Brilhar: brinquedoteca, literatura e arte no ambiente 
Crianças e adolescentes que voam em jaulas: a tecnologia promovendo a liberdade...

hospitalar", em conjunto com duas professoras do Departamento de Educação da UEPG e vinte alunos dos cursos de Pedagogia, Letras e Artes, realizamos atividades recreativas neste hospital, que atende, em sua maioria, casos oncológicos. Novamente, outras características e aprendizados estão sendo constituídos.

O que foi possível verificar nestes diferentes hospitais é que existe um aspecto comum na condição das crianças e dos adolescentes nestas diferentes regiōes do Brasil. As doenças não escolhem classe social, pois atingem crianças e adolescentes, indistintamente. Nos casos das doenças crônicas, as internações por longos períodos levam as crianças e adolescentes a permanecerem afastados de seus amigos, familiares, escola e objetos. Muitas vezes, a rudeza no tratamento, os procedimentos evasivos e as situações encontradas no hospital favorecem um afastamento do universo infanto-juvenil. Os pacientes ficam presos as suas patologias, a um ambiente que não é o seu e a um destino incerto.

A internação parece trazer uma ruptura das pessoas com o mundo externo. É como se existisse uma pausa de um mundo natural e construção de um outro mundo no hospital, cerceado por algumas paredes, muros, regras e interações. Para algumas pessoas, a internação é um momento de sofrimento, para outras, de redefinições. Porém, algumas privações não deixam de existir.

A utilização da metáfora "crianças e adolescentes que voam em jaulas" foi proveniente da leitura de uma poesia de Galeano (2001), que auxiliou na reflexão sobre a condição de vida das crianças e adolescentes nas sociedades contemporâneas. Este autor descreve que, independente de classe social, muitas crianças estão fadadas a determinados tipos de aprisionamento, dados os interesses que circundam as sociedades onde vivem:

Los echos se burlam de los derechos. Retrato de América Latina al fin del milenio: ésta es una región del mundo que niega a sus niños el derecho de ser niños. Los niños son los más presos entre todos los presos, en esta gran jaula donde se obliga a la gente a devorase entre sí. El sistema de poder, que nos acepta más vinculo que é pánico mutuo, maltrata a los ninôs. A los ninôs pobres los trata como si fueram basura. Los ninôs ricos los trata como si fueram mercadancia. Y a los de medio los tiene atados a la pata del televisor. (Galeano, 2001, p. 1)

A condição das crianças e adolescentes hospitalizados é de privação de liberdade e muito parecida com a situação de muitas crianças e 
adolescentes que moram nos grandes centros e que enfrentam a violência urbana e são restritos em suas possibilidades interativas. O ideal é que todos pudessem brincar livremente, correr pelas ruas, jogar bola, visitar os amigos e que fosse possível desfrutarem da infância e juventude de forma plena e sadia. Mas, assim como descreve Galeano (2001), as desigualdades sociais e os sistemas de poder enclausuram nossas crianças e adolescentes.

No caso das crianças e adolescentes hospitalizados, eles vivenciam uma série de regras na internação, como horários de medicação, alimentação e visitas. Estas regras também se fazem presentes na higiene pessoal e dos objetos para evitar infecçōes hospitalares. As normas fazem parte do aprendizado e convivência necessários nas instituições hospitalares. Nos casos de isolamento, as interações sociais são restritas, com regras claras e precisas. Se, por um lado, as crianças e adolescentes hospitalizados aprendem a incorporar essas normas no cuidado de si, por outro lado, eles também aprendem a re-elaborar estas regras, principalmente no que se refere às interações sociais. Nesse sentido é que a tecnologia utilizada por professores e profissionais, os quais trabalham com a humanização na saúde, tem auxiliado a transformar esses ambientes.

Este texto é um convite ao leitor para "voar junto com as crianças e adolescentes que vivem em jaulas", no caso, os hospitais. Em algumas situações, os vôos são cerceados, limitados por algumas paredes e até mesmo por regras e pessoas. Porém, estes elementos não impedem que eles sejam livres para "voar" em atitudes e pensamentos, pois são capazes de sonhar, fantasiar e re-inventar estes ambientes.

\section{A educação nos hospitais em diferentes regiōes e suas características}

$\mathrm{Na}$ atuação como professora e pesquisadora da educação nos hospitais, foi possível perceber que as crianças e adolescentes não reproduziam os estigmas de pessoas indiferentes as suas condições de vida e saúde. Este aspecto demonstrava que os tempos são outros e que somos outros também. Certamente, o movimento dinâmico da história não nos torna linear.

Nestes hospitais, foi possível observar que muitas crianças e adolescentes reclamavam das condições às quais estavam submetidos e procuravam meios para sobreviver de uma forma mais agradável durante a 
Crianças e adolescentes que voam em jaulas: a tecnologia promovendo a liberdade...

hospitalização. Dentre as estratégias por eles utilizadas, estavam as brincadeiras que realizavam com os seus companheiros de leito. Quanto eles tinham acesso à tecnologia, ao computador, aos jogos eletrônicos e vídeo, estas possibilidades eram ampliadas.

Para Steinberg (1997), os tempos modernos inauguraram uma nova era da infância, a qual ela denominou de kindercultura. Para a autora, essa nova geração tem abalado as noções tradicionais de infância e juventude devido à significativa influência da explosão das informações para estas populações. Nesse sentido, ela defende que o acesso infantil às informações está mudando de forma drástica a noção de infância e juventude e as formas interativas entre adultos, crianças e jovens.

Os espaços de aprendizagem não estão mais circunscritos a espaços familiares e escolares. Para Steinberg, as sociedades atuais têm gerado a pedagogia cultural na qual as aprendizagens ocorrem em várias instâncias, denominadas pela autora como locais pedagógicos: "Locais pedagógicos são aqueles onde o poder se organiza e se exercita como bibliotecas, TV, filmes, jornais, revistas, brinquedos, anúncios, videogames, livros, esportes, etc." (Steinberg, 1997, p. 102).

A vivência em diferentes ambientes sociais e pedagógicos, o acesso a diferentes fontes de informação e as posturas diante dos pais estão auxiliando na construção de um conceito de infância e juventude diferente de algumas décadas atrás. As crianças e adolescentes, atualmente, são pessoas que trocam, negociam e compartilham informações.

Alguns estudiosos consideram que há uma crise de valores em relação à infância e a juventude, outros consideram que estamos vivendo um momento de transição, até mesmo na definição destes conceitos.

No que se refere à noção de crise, Schramn (1996), ao analisar o conceito semântico e a origem da palavra crise, descreve que Krísis teve sua origem na Antigüidade grega e surgiu na linguagem religiosa com o sentido de decisão. Em nossa época, considerada de transição paradigmática, esta palavra assume o sentido de indecisão. Dessa forma, como as sociedades modernas são complexas, o autor considera que o conceito de crise vem sendo afetado pela polissemia da palavra e suas implicaçóes em diferentes áreas. Essa polissemia da palavra não deixaria de indicar uma situação de incertezas e tensões sociais. Sendo assim, ele considera que o termo crise se torna onipotente, mas, também, ambivalente. Ao mesmo tempo, reflete momentos de decisões e indecisões e corresponde 
também a um período de bifurcação: a crise pode gerar tanto uma catástrofe, como pode também criar soluções emergentes para conflitos.

A crescente relação dos homens com a tecnologia, para muitos, tem sido interpretada como um momento de crise das relações humanas, pois, nesta perspectiva, a tecnologia está cada vez mais afastando os homens dos contatos sociais. Contudo, também existe a defesa de que a relação do homem com a tecnologia tem oportunizado possibilidades interativas diferenciadas das que ocorriam nas sociedades mais tradicionais.

Ao analisar a influência da tecnologia no desenvolvimento humano, mais especificamente sobre as interações que ela tem propiciado para as crianças americanas, Tapscott (1999) descreve como a autoridade dos pais tem sido modificada em função do contato dos filhos com a tecnologia. Muitas vezes, os filhos, por terem mais informações que os pais nessa área tecnológica, têm educado os pais nesse processo. Dessa forma, o conceito de criança e adolescente vem se modificando por meio deste novo protagonismo infantil.

$\mathrm{Na}$ atuação como professora, o protagonismo era visível nas açōes das crianças e adolescentes hospitalizados. Eles demonstravam uma capacidade expressiva de regeneração física, emocional e de tomada de atitudes. Não se pode romantizar e afirmar que todos enfrentavam a hospitalização do mesmo modo. Existiam diferenças na emoção e na própria capacidade de resistência física, que eram limitadas pelas doenças. Mas, de modo geral, as crianças e adolescentes demonstravam uma capacidade significativa de superação das dificuldades que as doenças lhes impunham. Eles revelavam suas potências e capacidades de enfrentamento da situação, elaborando estratégias criativas através dos "vôos" que realizavam naquelas "jaulas", ou seja, nas enfermarias dos hospitais. Quando seus desejos e interesses eram respeitados e lhes eram oferecidas diferentes oportunidades, eles criavam e re-elaboravam suas capacidades. A tecnologia, em muitos momentos, era mediadora destes processos.

No caso das crianças e adolescentes do Hospital Sarah, de Brasília, pelo fato do mesmo ser voltado para doenças do aparelho locomotor, as deficiências físicas eram predominantes, principalmente derivadas de acidentes de trânsito. Desta maneira, muitas cadeiras de rodas eram utilizadas por crianças e adolescentes. Em muitos momentos, elas serviam como instrumentos para as brincadeiras de corridas e competiçóes, principalmente quando eram motorizadas. Para pacientes com comprometimentos 
Crianças e adolescentes que voam em jaulas: a tecnologia promovendo a liberdade...

físicos graves, também existiam computadores com telas sensíveis ao toque e outros formatos, denominados de comunicação alternativa, que possibilitavam diversas expressões.

O Hospital Sarah de São Luís do Maranhão também era voltado para as doenças do aparelho locomotor. Entretanto, o que chamava a atenção era a influência da televisão para as pessoas que estavam nas enfermarias e assistiam às programações. Cabe destacar que, em junho, nos períodos das festas do "Bumba-meu-boi", as relações entre as pessoas assumiam outras características. Existia, nas enfermarias, um trabalho coletivo muito expressivo de organização desta festa, perpetuação da cultura e da tradição local.

Neste período, a televisão era esquecida e as enfermarias eram palcos de criação das roupas do "bumba meu boi", de produção de enfeites repletos de significados nos leitos, de ensaio das danças e de divulgação das novas músicas. Esses elementos expressavam a cultura popular e a religiosidade ${ }^{1}$ das crianças, dos adolescentes e seus familiares. Entretanto, em outros períodos, no cotidiano das enfermarias, o horário das novelas era "sagrado" para todos. Salgado, Pereira e Souza (2005, p. 1), ao analisarem o hábito e os modos de ver televisão, observaram que:

A rapidez tem se caracterizado como o símbolo desta nossa época. E a linguagem televisiva talvez seja seu maior emblema. Rápida, precisa, objetiva. Em casa (muitas vezes em mais de um cômodo), em bares, restaurantes, boates, consultórios, ônibus e táxis, lá está ela - a televisão. Mantê-la ligada é promessa de companhia. Seus ruídos são como canções de ninar. Seus sons e imagens, habitantes apressados desta nova cidade eletrônica, sobrepóem-se sem se deixar fixar, meio sem rosto, num eterno despedirse. Em meio a tanta pressa, ficamos à vontade, isentos do compromisso de vê-los ou ouvi-los. Educados para a dispersão, construímos um outro olhar, calcado na intermitência, dificultando a reflexão.

No caso deste hospital público, como existia uma única televisão para todos assistirem às novelas, era uma espécie de ritual. As famílias se reuniam em círculos, como se fossem as antigas rodas de histórias, e sentavam-se para assistir, conversar, rir e discutir sobre as novelas. De certa forma, a televisão expressava um pouco da continuidade da casa, da rotina familiar. As novelas também possuíam o efeito de compartilhar histórias e experiências. Assistir a uma novela não era somente um meio de entretenimento para as crianças, os adolescentes e suas famílias. Era uma 
das formas pelas quais eles entravam em contato com o mundo externo. Era um meio de "voarem" por algumas horas, nos dramas e nas comédias daquelas imagens.

Há de se considerar que, muitas vezes, as famílias viam suas dores expressas na tela da TV. No Brasil, de uns anos para cá, algumas novelas têm procurado incluir questóes relacionadas à área de saúde no desenrolar dos dramas. As novelas começaram a ser veículos de campanhas para doação e transplante de órgãos, explicação de doenças, informaçôes sobre drogas, alcoolismo, deficiências, entre outras questôes.

Todavia, embora as novelas assumissem no hospital um importante papel para distração das crianças e adolescentes, eles não se contentavam com esta programação. Estas não eram suas distraçōes principais. Apesar de se divertirem com alguns personagens, imitando-os, suas preferências estavam voltadas para filmes e desenhos animados. Para os adultos, em muitos momentos, assistir à televisão representava um ato de contemplação das imagens e fuga da realidade hospitalar.

Algumas crianças e adolescentes pediam para permanecer o dia todo assistindo à televisão. Este fato gerava conflito entre eles, a equipe de enfermagem e até mesmo com os professores, os quais, em muitos momentos, tinham que seduzir as crianças para realizarem outras atividades lúdicas e, também, as escolares. Neste sentido, em muitos momentos, os professores competiam com as programaçōes televisivas infantis. A participação dos alunos nas aulas e atividades nos hospitais não era obrigatória. Entretanto, este trabalho era uma maneira das crianças e adolescentes conviverem com outras pessoas, trocarem idéias, conhecimentos, discutirem a hospitalização e darem continuidade a seus estudos.

Para as crianças e adolescentes que não podiam sair dos leitos a televisão era muito agradável. Mas, ao mesmo tempo, assistir à televisão em tempo integral também gerava angústia e tédio. As crianças e adolescentes percebiam este aspecto e solicitavam outras opçôes. Queriam "voar mais alto".

Com o tempo, o hospital inseriu o vídeo nas enfermarias. Há de se considerar a influência de algumas corporaçōes internacionais e de filmes brasileiros que faziam sucesso entre as crianças e os adolescentes. Eles adoravam filmes como $O$ pestinha, Esqueceram de mim, Os Trapalhôes, filmes da Walt Disney, desenhos animados, entre outros. O 
Crianças e adolescentes que voam em jaulas: a tecnologia promovendo a liberdade...

que chamava a atenção é que, nestes filmes, as narrativas eram de humor, muita comédia e havia uma bela estética nas imagens e nos desenhos. Nestes filmes e desenhos prediletos, existia a idéia da subversão da ordem, do poder e de comportamentos alterados das crianças, personagens principais das histórias. Era como se esses filmes libertassem as crianças e adolescentes hospitalizados da situação de restrições. Para Salgado, Pereira e Souza (2005, p. 2):

Os programas televisivos voltados ao público infantil, como desenhos animados, anúncios publicitários, entre outros, podem ser considerados discursos culturais, voltados para a criança, sobre a vida social, que lhe sugerem um posicionamento sobre o mundo (Brougère, 1995). São, portanto, enunciados que expressam formas de conceber a infância no mundo contemporâneo e de estabelecer diálogos com as crianças, convidando-as a participarem do mundo. Diante disto, pretendemos compreender como e de que forma as crianças se apropriam desses enunciados, como manipulam e interagem com esses discursos e como estes, por sua vez, participam do processo de constituição de sua subjetividade, sem perder de vista a dialogia aí também presente, pois esse processo implica escolhas e assimilaçôes dos discursos alheios. Para Bakhtin (1992), o discurso que vem do outro, aberto a transformações, penetra em nossa consciência, provocando o nosso discurso como resposta, a contrapalavra.

Aquelas opções de filmes e desenhos revelavam os sentimentos, desejos e discursos não ditos das crianças e adolescentes hospitalizados.

Outros episódios interativos ocorridos com a presença de tecnologia no hospital estiveram relacionados com o cinema. Por iniciativa de um médico, naquela época, diretor-clínico do Hospital Sarah, foi realizado um convênio com um cineclube da cidade de São Luís. Em alguns sábados, eram projetados filmes em $16 \mathrm{~mm}$ para as crianças, adolescentes e seus familiares. Assim, famílias do interior do Maranhão, que jamais tinham ido a um cinema, puderam, reunidas, ver imagens projetadas nas paredes do hospital. Certamente, depois daquelas sessóes de cinema, as crianças, os adolescentes e seus familiares não foram mais os mesmos.

Também é preciso destacar a influência da TV, principalmente dos Programas TV Educativa das Escolas do Ensino Fundamental do Maranhão. Estes programas auxiliavam o trabalho dos professores hospitalares na continuidade da escolarização das crianças e adolescentes 
que permaneciam internados por longos períodos. Neles existiam livros didáticos que estavam relacionados à educação a distância. Naquele período, os programas da TV Educativa eram precários no que se refere ao roteiro, produção e edição dos vídeos, pois eram feitos com pouca sofisticação e preocupação estética. Entretanto, era um recurso significativo para as crianças e adolescentes hospitalizados, que podiam acompanhar os mesmos conteúdos que estavam sendo ministrados nas suas escolas de origem. Os alunos que acompanharam estes programas no hospital não foram reprovados em suas escolas.

Em Portugal, Ribeiro (2000) tem defendido a implantação de programas de educação a distância para continuidade da escolarização de crianças e adolescentes hospitalizados.

Outro aspecto referente à tecnologia esteve relacionado à implantação dos computadores nas enfermarias. Por volta de 1995, eles surgiram como instrumento de trabalho dos profissionais do hospital para registro da evolução dos pacientes nos prontuários informatizados. Porém, quando foram implantados jogos no computador, estes se transformaram em verdadeiros brinquedos e causaram uma verdadeira revolução nas enfermarias. Quando os pacientes aprenderam a lidar com os computadores, tomaram posse dos mesmos e dificultaram o acesso da equipe de enfermagem para utilizá-los. Os professores precisavam negociar horários com as crianças e adolescentes para que a equipe de enfermagem e os médicos pudessem utilizá-los.

Algumas crianças e adolescentes que nunca tinham ido para a escola, por meio das brincadeiras e dos jogos no computador, começaram a desenvolver interesse pela alfabetização. O computador tornouse uma necessidade fundamental. Quanto à Internet, naquela época, ainda não havia sido implantada no hospital, portanto as crianças não a conheceram. Certamente, outras possibilidades teriam surgido.

Em relação ao papel da tecnologia nos projetos desenvolvidos nos hospitais do Paraná, um aspecto observado foi a importância das fotografias para as crianças e adolescentes hospitalizados. $\mathrm{O}$ primeiro projeto de extensão do qual participei era esporádico e ocorria somente uma vez por semana nos hospitais. Desta maneira, os vínculos afetivos eram diferenciados. Contudo, o que foi possível observar é que muitas crianças e adolescentes jamais haviam tido a oportunidade de serem fotografados. Era como se fossem excluídos da imagem. No hospital, durante o 
Crianças e adolescentes que voam em jaulas: a tecnologia promovendo a liberdade...

projeto de extensão, as vidas eram fotografadas, registradas e depois entregues aos seus familiares.

Estas ações eram mediadoras do processo de inclusão daquelas pessoas no universo imagético. Nesses momentos, o paradoxo da realidade hospitalar se fazia presente, pois ao mesmo tempo em que aquele era um espaço da dor, para muitos, também representava a única oportunidade de terem suas vidas registradas no papel fotográfico. Naqueles retratos, as pessoas não estavam levando somente a imagem do hospital para suas casas, mas também estavam carregando lembranças, sentimentos, histórias e afetos.

No Hospital Filantrópico da Bahia, a tecnologia foi decisiva para modificar os rumos da tese e a concepção de crianças e adolescentes hospitalizados. A pesquisa teórico-metodológica da etnopesquisa, proposta por Macedo (2000), auxiliou no olhar, na escuta sensível dos atores sociais, na descrição e análise da realidade daquela escola no hospital.

A pesquisa de campo configurou-se como um estudo de caso qualitativo. Durante um ano, foi realizada a coleta de dados. Os procedimentos éticos ${ }^{2}$ se manifestaram desde o ingresso no campo até a restituição do trabalho. Foram utilizados vários instrumentos para captar a realidade, tais como observações das aulas gravadas em vídeo, registros em diário de campo, análise de documentos e entrevistas. No total, foram registradas 55 observações das aulas das duas professoras: da educação infantil e do ensino fundamental e médio.

Destas observações, 31 aulas foram registradas em diário de campo (sem a presença da câmera), pois a intenção era criar uma familiaridade com o ambiente para uma melhor aproximação e confiança com as pessoas. Posteriormente, foram gravadas em vídeo 24 aulas das professoras. Nas gravações, antes do seu início, eram realizadas explicações e esclarecimentos sobre os objetivos da pesquisa. Em seguida, as pessoas autorizavam por escrito, por meio do consentimento informado, a utilização de suas imagens. Neste processo, poucas pessoas se recusaram a serem fotografadas ou filmadas.

As crianças da educação infantil gostavam de se ver na TV, mas não demonstraram interesse em filmar. No entanto, as crianças e os adolescentes que participavam das aulas da professora do ensino fundamental e médio expressaram forte desejo de se apropriar do equipamento e explorá-lo nas mais diversas circunstâncias. 
A professora do ensino fundamental e médio da escola no hospital era uma profissional aberta a novas propostas e inseriu a gravação em vídeo nas suas aulas com muita tranqüilidade. Os alunos, por sua vez, não foram resistentes em nenhum momento à introdução da câmera naquele contexto. Era como se os alunos quisessem ver e desvelar a escola do hospital não somente com os seus olhos, mas a partir da lente da câmera. Através das filmagens, eles procuravam mostrar as alegrias, tristezas e contradições do ambiente hospitalar.

É preciso destacar que as salas de aula nos hospitais eram multisseriadas, com alunos provenientes de diferentes cidades, níveis de escolaridade e patologias diversas. Portanto, vários olhares, diferentes concepçôes culturais se mesclavam na escola no hospital.

O exercício de contemplar o interior da classe hospitalar pelas lentes da câmera foi realizado de forma expressiva no dia 16/05/2003. Naquele dia, os alunos reivindicaram à professora do ensino fundamental e à pesquisadora que eles seriam responsáveis por filmar a aula. A professora aceitou o convite e, em conjunto com os alunos, elaborou um roteiro de perguntas para entrevistar os familiares das crianças que estavam nas enfermarias. $\mathrm{O}$ objetivo do trabalho era que os pais contassem suas experiências de escolas na infância. Na produção do roteiro, os alunos, através de suas vozes, apresentaram indagaçôes que possuíam a respeito da organização das escolas no passado e também esboçaram os sonhos que possuíam das escolas que desejam para o futuro. Neste processo de preparação do trabalho foi realizada uma eleição, na qual, democraticamente, foram escolhidos o repórter e o cinegrafista.

Antes das gravaçōes serem iniciadas, foram repassados alguns conhecimentos técnicos a respeito da utilização da câmera, mas os aprendizes, no estilo do cinegrafista baiano Glauber Rocha, demonstraram que queriam agir com uma "câmera na mão e mil idéias na cabeça". Portanto, com a "câmera nas mãos", criativamente eles assumiram a direção do trabalho, da aula e da pesquisa. Desta maneira, foram para os leitos e, nos diálogos realizados com as geraçôes mais antigas e as mais novas, puderam conhecer diferentes mundos.

Aquela aula demonstrou as possibilidades que a câmera de vídeo, a televisão e as imagens trouxeram para a escola-hospital. Em um primeiro momento, o fato das crianças e seus familiares poderem se ver na televisão do hospital fez com que eles se sentissem incluídos na dinâmica 
social e televisiva. Mas se, em princípio, havia um contentamento com esta situação, com o tempo, as crianças não queriam somente ver suas imagens refletidas no espelho da TV, este aspecto já não lhes era mais suficiente. Assim como o mito de Narciso, as crianças inicialmente sentiram-se seduzidas por verem suas imagens no "espelho" da televisão, mas elas não queriam ser devoradas por esse espelho e foram inventando outros movimentos. Elas continuavam reivindicando a retratação de suas imagens, mas também solicitavam levar esses espelhos para seus amigos e familiares que estavam nas enfermarias. As crianças também não queriam somente ser observadas e se observarem na televisão, mas de observadas passaram a ser observadoras. Esse movimento das imagens possibilitou àquelas crianças e adolescentes sentirem-se pessoas capazes, quebrando paradigmas de passividade.

A produção do vídeo pelas crianças e adolescentes possibilitou entender a importância do uso da tecnologia para intermediar ações diferenciadas no ambiente da escola no hospital e compreender a forma com a qual aqueles alunos-pacientes queriam agir, não somente sendo usuários do serviço de saúde e educação, mas participando, construindo e transformando a realidade e o cotidiano hospitalar.

Atualmente, na brinquedoteca e no projeto de extensão que desenvolvo no Hospital Bom Jesus no Paraná, os brinquedos mais solicitados pelas crianças são: videogames, computadores, MP3 e, inusitadamente, DVDs com karaokês. Soltar a voz e cantar também são expressões de liberdade para as crianças e adolescentes paranaenses que estão internados.

\section{Considerações finais}

A intenção deste artigo foi demonstrar a presença e importância que a tecnologia representa nas enfermarias dos hospitais brasileiros, para auxiliar às crianças e adolescentes hospitalizados a conhecerem diferentes possibilidades interativas neste ambiente. Com este recurso, eles podem "voar" alto, mesmo diante de limites e restriçôes.

Outro aspecto que foi evidenciado nestes hospitais é que muitas daquelas crianças e adolescentes tiveram o seu primeiro contato com fotografias, computadores e vídeo somente no hospital. Neste sentido, convencionalmente conhecido como espaço da dor, foi vivenciado como 
espaço do lúdico e de novos conhecimentos. Isso nos leva a pensar que as escolas de origem de muitas crianças e adolescentes hospitalizados precisam ser mais bem aparelhadas. Também se faz necessária a democratização da tecnologia para que, em redes, possam ser criados novos elos e possibilidades de "vôos" para que todas as crianças e adolescentes possam usar este instrumento como práticas de liberdade.

Recebido em abril de 2007 e aprovado em outubro de 2007.

\section{Notas}

1. É preciso destacar que a festa do "Bumba-meu-boi” é também uma festa religiosa. Os bordados do manto do boi refletem as promessas da comunidade. A festa se inicia dia 24 de junho - dia de São João - e seu término é no dia 29 de junho - dia de São Pedro. No Maranhão, existem diferentes tipos de "bumba-meu-boi" e seus sotaques. Os grupos apresentam roupas, músicas e danças diferenciadas, mas todos refletem a lenda de Pai Francisco e Catirina.

2. A pesquisa foi aprovada pelo Comitê de Ética do Hospital Santo Antônio das Obras Sociais Irmã Dulce.

\section{Referências bibliográficas}

GALEANO, E. Educando con el ejemplo. Disponível em: <http:// www.patriagrande.net/uruguay/eduardo.galeano/patas.arriba/index.htm> Acesso em: 5 out. 2001.

MACEDO, R.S. A etnopesquisa critica e multirreferencial nas ciências humanas. Salvador: EDUFBA, 2000.

RIBEIRO, A.P. Do hospital à escola. In: REFLETIR AS PRÁTICAS PARA MELHORAR O DESEMPENHO, 1999, Porto. Actas do encontro... Lisboa: Instituto de Apoio à Criança, 2000, p. 49-56. (Humanização dos serviços de atendimento à criança).

SALGADO, R.G.; PEREIRA, R.M.R; SOUZA, S.J. Pela tela, pela janela: questões teóricas e práticas sobre infância e televisão. Cadernos CEDES, Campinas, v. 25, n. 65, p. 9-24, jan./abr. 2005.

SANTIAGO, R. Termina prazo para construção de brinquedotecas em hospitais. Folha on-line, São Paulo, 29/09/2005. Disponível em: 
Crianças e adolescentes que voam em jaulas: a tecnologia promovendo a liberdade...

<http://www1.folha.uol.com.br/folha/cotidiano/ult95u113304>. Acesso em: 2 jan. 2007

SCHRAMN, F.R. A terceira margem da saúde: ética natural, complexidade, crise e responsabilidade no saber-fazer sanitário. Brasília, DF: UNB, 1996.

STEINBERG, S.R. Kindercultura: a construção da infância pelas grandes corporações. In: SANTOS dos SANTOS, E. Identidade social e a construção do conhecimento. Porto Alegre: Prefeitura Municipal de Porto Alegre, Setor de Educação, 1997. p. 98-145.

TAPSCOTT, D. Geração digital: a crescente e irreversível ascensão da geração Net. São Paulo: Makron, 1999. 